\title{
TEMA: A Tecnologia Ecologicamente Mais Adequada Como Uma Estratégia Preventiva a Ser Perseguida
}

\author{
Marcelo Firpo de Souza Porto \\ Centro de Estudos de Saúde do Trabalhador e Ecologia Humana - \\ CESTEH/ENSP/FIOCRUZ - Rua Leopoldo Bulhões 1480 -Manguinhos - \\ CEP 21041-210 - Rio de Janeiro - RJ -Tel: (021)270-3219
}

\section{Ubirajara Aluizio de Oliveira Mattos}

Universidade do Estado do Rio de Janeiro - Faculdade de Engenharia - Departamento de Engenharia Sanitária - Rua São Francisco Xavier 524 Bloco A $5^{\circ}$ andar - Maracanã - CEP 20550-013 - Rio de Janeiro

Palavras-chave: tecnologia, mudança de; saúde dos trabalhadores; ecologia; indústria de cloro-soda.

\section{RESUMO}

A prevenção técnica dos riscos industriais pode envolver cinco níveis de atuação: os níveis do individuo/ trabalhador, do posto de trabalho, do setor de trabalho, da fábrica como um todo, e do meio ambiente em geral. Históricamente, tais níveis tenderam a serem analisados por disciplinas, métodos e instituições frequentemente dissociados uns dos outros.

Transpassando todos os níveis, a discussão sobre a base tecnológica de um dado setor industrial pode fomecer luzes importantes para entendermos a dinâmica dos riscos presentes e evitáveis numa determinada fábrica ou setor industrial, em articulação com as estratégias de investimentos produtivos e mudanças tecnológicas.

Neste contexto, a busca da Tecnologia Ecologicamente Mais Adequada - TEMA - pode ser um importante conceito preventivo, servindo para nortear os critérios dos investimentos produtivos em curso nos diferentes setores industriais do pais. A partir de um exemplo em andamento no Rio de Janeiro, envolvendo uma mudança negociada de tecnologia numa empresa de cloro-soda, este trabalho pretende apresentar alguns dos elementos que compõem a intrincada rede de interesses e possibilidades que estão por detrás da implementação da TEMA, envolvendo as dimensões social, econômica e tecnológica do problema. 


\section{Os Diferentes Níveis da}

Ação Preventiva e a

Prevenção Estrutural ao

Nível Tecnológico

A tabela apresentada mais à frente (Porto, 1994) mostra algumas modalidades de prevenção técnica possíveis, envolvendo os riscos de processos de trabalho industriais, de acordo com o nível da ação preventiva.

A mudança de um enfoque individualista punitivo para uma modalidade preventiva mais eficiente e sistêmica, vem ocorrendo, princi- palmente, a partir da década de 60 nos paises centrais, através do desenvolvimento de disciplinas e implementação de medidas mais coletivas e eficientes ao nível do controle dos riscos. A criação da Ergonomia e o desenvolvimento da Engenharia de Segurança Sistêmica são exemplos desse processo. No Brasil, contudo, principalmente só a partir dos anos 80 , é que vem se dando um processo de introdução de novos enfoques preventivos, em grande parte com a colaboração da própria engenharia de produção. Estes novos enfoques enfrentam ainda a hegemonia do enfoque individualista punitivo, presente amplamente na formação dos quase 120 mil profisssionais de segurança do trabalho formados nas décadas de 70 e 80 como resultado da política oficial preventiva do governo brasi-

\begin{tabular}{|c|c|c|}
\hline $\begin{array}{c}\text { Nível da Ação } \\
\text { Preventiva }\end{array}$ & $\begin{array}{c}\text { Exemplos de } \\
\text { Prevenção Possível }\end{array}$ & $\begin{array}{l}\text { Exemplos de Disciplinas } \\
\text { e Corporações Envolvidas }\end{array}$ \\
\hline $\begin{array}{c}1 \text { - Nível do Individuo } \\
\text { (Trabalhador) }\end{array}$ & $\begin{array}{l}\text { Equipamentos de Proteção (EPI) } \\
\text { Cumprimento de Normas de Segurança } \\
\text { Exames Médicos Periódicos }\end{array}$ & $\begin{array}{l}\text { Engenharia de Segurança, Medicina } \\
\text { do Trabalho, Psicologia do Trabalho }\end{array}$ \\
\hline $\begin{array}{l}2 \text { - Nivel do Posto } \\
\text { de Trabalho }\end{array}$ & Projeto Ergonômico do Posto de Trabalho & Ergonomia \\
\hline $\begin{array}{l}3 \text { - Nivel Coletivo do } \\
\text { Setor de Trabalho }\end{array}$ & $\begin{array}{l}\text { Equipamentos de Proteção Coletiva } \\
\text { Enclausuramento de Fontes de Risco através de Técnicas } \\
\text { Construtivas }\end{array}$ & $\begin{array}{l}\text { Engenharia de Segurança, Engenharias } \\
\text { Especiticas de acordo com o risco } \\
\text { envolvido (térmico, acústico, etc.) }\end{array}$ \\
\hline $\begin{array}{l}4 \text { - Nivel Coletivo } \\
\text { da Fábrica }\end{array}$ & $\begin{array}{l}\text { Política Tecnológica: Desenvolvimento e seleção do } \\
\text { processo e da TEMA (Tecnologia Ecologicamente Mais } \\
\text { Adequada); análise de riscos; construção e ativação da } \\
\text { produção segundo critérios preventivos adequados; } \\
\text { mudança de tecnologia. } \\
\text { Nivel Organizacional e Gerência de Risco: divisão e } \\
\text { intensificação do trabalho, política de treinamento e } \\
\text { tormação, possibilidades de participação pelos } \\
\text { trabalhadores, subcontratação, formas de incentivo e } \\
\text { coerção, estabelecimento e priorização da política } \\
\text { preventiva, responsabilidades na estrutura hierárquica, } \\
\text { planos de emergência, análise continuada e informaçào } \\
\text { sobre os riscos. }\end{array}$ & $\begin{array}{l}\text { Análise de Risco Tecnológico, } \\
\text { Engenharia de Segurança Sistêmica, } \\
\text { Engenharia de Processos, Engenharia } \\
\text { Civil, Economia e Análise de } \\
\text { Investimentos } \\
\\
\text { Organização do Trabillho, } \\
\text { Administração, Psicologia e } \\
\text { Sociologia do Trabalho, Ergonomia }\end{array}$ \\
\hline 5 - Ambiente Geral & $\begin{array}{l}\text { Politicas de Desenvolvimento Auto-Sustentável } \\
\text { Análise e Impacto Ambiental } \\
\text { Planejamento Territorial cm Áreas de Risco } \\
\text { Planos de Emergência off-site } \\
\text { Estruura Emergencial (combate, atendimento médico } \\
\text { emergencial, saneamento de áreas contaminadas) }\end{array}$ & $\begin{array}{l}\text { Análise de Risco Tecnológico; } \\
\text { Ecologia Aplicada, Ecotoxicologia, } \\
\text { Epidemiologia, Geografia, Economia, } \\
\text { Ciências Sociais e Polílicas. }\end{array}$ \\
\hline
\end{tabular}


leiro desta época (Dwyer, 1992). Além disso, as relações de trabalho autoritárias presentes em inúmeras empresas brasileiras - fenômeno que reflete as características sócio-políticas gerais do modelo de desenvolvimento sócioeconômico do país nas últimas décadas limitam as possibilidades de reivindicação e participação ativa dos trabalhadores nos locais de trabalho, condição sine qua non para a implementação de politicas efetivas de gerenciamento de risco.

As modalidades preventivas que envolvem o ambiente externo às fábricas são relativamente recentes, mesmo nos páses centrais, desenvolvidas principalmente após a intensificação da discussão ecológica e das catástrofes industriais de Sevezo, Bhopal e Chernobyl, entre outras. Nos países periféricos e de industrialização recente, este tema é ainda bastante incipiente, apesar da enorme gravidade do problema, verificada em acidentes como Bhopal, onde a ineficiência preventiva da multinacional americana Union Carbide, associada ao descontrole por parte das agências reguladoras indianas e à existência de uma área de risco altamente povoada e sem nenhum plano de emergência, provocou o maior acidente industrial da história: mais de 3000 mortes imediatas e de 200.000 pessoas intoxicadas. A tragédia está presente ainda hoje, não só na memória dos sobreviventes, mas também nos recém-nascidos deficientes e nas mortes semanais decorrentes da exposição ao extremamente tóxico MDI -metil diisocianato-(Jasanoff, 1988; Caslleman, 1987). Apesar do ocorrido, o potencial de novas tragédias semelhantes faz parte da realidade latino-americana e brasileira, e poucas ações tem sido feitas até agora para reverter de forma efetiva este quadro.

\section{A Tecnologia Ecologicamente Mais Adequada - TEMA - como Estratégia Preventiva}

A presença e repetição de determinados acidentes, doenças e outros distúrbios de saúde, demonstram os limites de um dado modelo preventivo e a necessidade de seu contínuo aperfeiçoamento. A gravidade dos conflitos ecológicos e de saúde podem apontar para os riscos intrínsicos de tecnologias e unidades produtivas existentes. Neste caso, somente mudanças ao nivel estrutural resolveriam o problema, através de mudanças mais radicais nas relações técnicas e organizacionais da empresa. É neste contexto que podemos falar de uma prevenção est rutural ao nível tecnológico, sem a qual os riscos industriais e cargas de trabalho continuariam a prejudicar a saúde e o meio-ambiente.

Em termos tecnológicos, tal prevenção poderia envolver, por exemplo, a proibição ou redirecionamento de certas tecnologias produtivas existentes; a incorporação de critérios ecológicos e de saúde nas fases de elaboração, experimentação e construção de tecnologias de processo, de produtos e construção/ampliação de unidades industriais. A existência de condições políticas, técnicas e institucionais para a introdução da TEMA Tecnologia Ecologicamente Mais Adequadaem todos os setores industriais de um pais pode servir como um dos elementos centrais na formulação das politicas setoriais de desenvolvimento. 
Nem sempre podemos eleger uma TEMA dentre as tecnologias produtivas existentes para a fabricação de um produto particular. Eventualmente, todas as tecnologias técnicas e economicamente viáveis possuem riscos para a saúde e o meio ambiente não claramente superiores uns aos outros. Contudo, podem existir situações onde uma tecnologia seja claramente, do ponto de vista ecológico e da saúde dos trabalhadores, mais adequada. Normalmente, a existência de uma TEMA em um setor econômico específico não é pura casualidade, mas sim o resultado de investimentos e esforços continuados na busca de soluções técnicas adequadas para a superação de certos riscos existentes. Muitas vezes são necessárias tragédias, como mortes, doenças ocupacionais e catástrofes ambientais, articulados com movimentos políticos reivindicatórios de grupos sociais atingidos e solidários, para que o surgimento e difusão de uma TEMA ocorra. Este foi justamente o caso da tecnologia de membrana na produção de cloro-soda e do acordo que visou a implementação de tal tecnologia numa indústria carioca, como aprofundaremos a seguir.

\section{O Caso da Indústria de Cloro-Soda}

Existem três processos de eletrólise distintos, atualmente em uso no mundo para a produção de cloro. Os mais antigos são o processo de amálgama, que utiliza o mercúrio metálico como catodo da célula eletrolítica e corresponde a cerca de $40 \%$ da produção mundial (13mtpa), e o denominado processo de diafragma, que se utiliza de um diafragma poroso à base de asbesto para separar as áreas anódica da catódica. Este tipo de processo é responsável por $45 \%$ da produção mundial, localizando-se principalmente nos EUA. O terceiro é o processo de membrana, utilizado na produção industrial somente a partir da segunda metade dos anos 70 , sendo este responsável por $15 \%$ da produção mundial no início dos anos 90. Esta tecnologia se utiliza de uma membrana semipermeável por onde passam somente ions de sódio e um pouco d'água. Além do menor consumo de energia elétrica, uma das principais vantagens alegadas para o seu desenvolvimento é a não utilização do mercúrio metálico e do asbesto nas células, sendo considerada atualmente a tecnologia ecologicamente mais adequada para a fabricação do cloro.

Um fator importante no desenvolvimento tecnológico e implementação do processo de membrana deveu-se, além das fortes pressões decorrentes dos movimentos ambientalistas e sindicais dos paises industrializados, à tragédia na Baía de Minamata no Japão, que acelerou as medidas de controle ambiental e ocupacional do mercúrio naquele pais. A tragédia ocorreu através da poluição de uma baía semifechada por uma fábrica química produtora de acetaldeído, um componente usado na produção de fertilizantes, plásticos, entre outros. A fábrica usava o mercúrio como catalisador em seu processo, e a emissão aquática contínua na baía proporcionou a metilação do mercúrio orgânico e sua incorporação na cadeia alimentar, contaminando os habitantes da região através da ingestão de peixe. Desde 1956, quando a primeira doença tornou-se evidente, até 1989 mais de 20.000 pessoas foram afetadas (Maxson et al., 1991). Isso justifica porque o Japão é um dos dois únicos países que proibiu o uso do processo de amálgama (o outro é Formosa, possivelmente pela influência japonesa), sendo o maior produtor de cloro com a tecnologia de membrana do mundo. Isto mostra como o desenvolvimento de tecnologias ecologicamente adequadas ou "limpas" são obtidas a partir de pressões políticas, muitas vezes posteriores a ocorrência de tra- 
gédias, que forçam a introdução de critérios ecológicos e de saúde na delimitação dos projetos tecnológicos.

\section{Um Caso de Mudança Negociada de Tecnologia no Rio de Janeiro}

Em 1992 foi realizado um acordo pioneiro no país, entre diversos atores sociais, envolvendo a mudança de tecnologia numa empresa produtora de cloro instalada na cidade do Rio de Janeiro. A tecnologia de mercúrio, adotada nas células eletrolíticas da empresa, encontrava-se em elevado nivel de obsolescência, contaminando trabalhadores e o próprio meio ambiente.

Tal negociação, de caráter simultaneamente técnico e político, envolveu diversos atores com interesses eventualmente conflitantes nas diversas fases onde o problema foi discutido e decisões foram tomadas. A decisão final foi possível através do financiamento especial do BNDES para a ampliação industrial da fábrica em questão, o que forneceu o substrato financeiro para o compromisso estabelecido entre a empresa, autoridades e o sindicato. Tal processo, envolvendo uma enorme teia de relações políticas, técnicas e institucionais nas diferentes fases que compuseram o processo de negociação, mostra que a mudança tecnológica em função de critérios ecológicos e de saúde num setor industrial especifico só pode ser realizada através da mobilização de um conjunto expressivo de atores sociais organizados em torno de certos objetivos comuns, face à complexidade política, econômica e técnica envolvidas. Além do sindicato dos trabalhadores, o envolvimento de autoridades do poder público e legislativo e instituições técnicas, respaldadas também por reivindicações ecológicas e de moradores, foi fundamental para que tal acordo fosse processado.

Em outras palavras, se tais atores não tivessem se mobilizado- ou apenas uma parcela insuficiente para gerar as argumentações técnicas e constelações políticas necessárias - tal acordo não poderia ser realizado. Ou seja, a mudança de tecnologia por critérios ecológicose de saúde não se viabiliza somente através das argumentações técnicas e econômicas, mas, fundamentalmente, pela junção entre pressões politicas dos grupos interessados e autoridades abertas a tais reivindicações, e dispostas a encontrarem soluções para elas. Isto mostra a intrínseca relação existente entre o controle dos riscos industriais e o processo de democratizaçãodopaís.

\section{Perspectivas Futuras de Implantação da TEMA no Setor de Cloro-Soda no Brasil}

Em 1990, a capacidade de produção de soda cáustica instalada no país era a seguinte:

\begin{tabular}{|l|c|c|}
\hline \multicolumn{1}{|c|}{$\begin{array}{c}\text { Especificaçāo } \\
\text { (Produto/Tecnologia) }\end{array}$} & $\begin{array}{c}\text { Capacidade } \\
\left(10^{3} \text { ton) }\right.\end{array}$ & Percentual \\
\hline Soda Cáustica & $\underline{1232}$ & $\underline{100 \%}$ \\
\hline Tecnologia de Amálgama & 343 & $28 \%$ \\
Tecnologia de Diafragma & 871 & $71 \%$ \\
Tecnologia de Membrana & 18 & $1 \%$ \\
\hline Potassa Cáustica (Tecnol. & 23 & $100 \%$ \\
\hline Amálgama & & \\
\hline
\end{tabular}

Fonte: Abiclor, 1992.

A partir da segunda metade dos anos 60 , os novos investimentos para a produção de cloro 
se concentram na indústria da celulose, em regiões onde foram implantados grandes projetos industriais envolvendo a plantação de eucaliptos em extensas áreas florestais para a produção de papel, com o predomínio da tecnologia de diafragma e, mais recentemente, a introdução da tecnologia de membrana. Esta tendência continua a ser uma das principais razões de investimentos produtivos no país nos últimos anos, que vem aumentando fortemente a participação da tecnologia de membrana no país. Em 1990, menos de 2\% da produção nacional de soda cáustica ficava por conta de células de membrana, enquanto $28 \%$ era produzido por células de mercúrio e cerca de $70 \%$ por células de diafragma. De acordo com entrevistas com técnicos brasileiros e europeus deste setor industrial, houve um crescimento expressivo no início dos anos 90 das células com tecnologia de membrana no país.

As características destes investimentos recentes, contudo, parecem restringirem-se à expansão da indústria nacional de celulose, que produz cloro para o auto-consumo, e não para as indústrias clássicas de cloro-soda revendedoras de cloro. Estas continuam a produzir, principalmente a partir da tecnologia de amálgama, sem perspectivas oficiais de reconversão tecnológica, conforme pode ser apreendido no documento que marca a posição do setor industrial sobre o assunto (Abiclor, 1992). Segundo este documento, a substituição das células à base de mercúrio demandaria muito tempo - são citados os 16 anos gastos pelo Japão e o plano de 20 anos previsto na Europa - e dinheiro, envolvendo valores na ordem de 300 milhões de dólares para as 343 mil toneladas produzidas anualmente pela tecnologia de amálgama no país.

Ao nosso ver, o argumento do tempo reflete uma característica nacional típica: o des- prezo pela necessidade do planejamento de longo prazo. Tal ordem de grandeza no planejamento do desenvolvimento industrial e controle ambiental é considerado um tempo absolutamente normal e necessário em muitos paises industrializados. $\mathrm{O}$ argumento financeiro deveria ser contextualizado de forma mais objetiva em relação às perspectivas do setor e à viabilidade de novos investimentos, até mesmo porque tais cifras tornam-se pequenas diante dos 2,5 bilhões de dólares movimentados anualmente pelo setor, segundo consta no próprio documento da ABICLOR. Outro aspecto refere-se à forma como os custos relacionados aos problemas ambientais e de saúde são, ou melhor, não são computados nos custos gerais da mudança tecnológica.

\section{Conclusão}

A implementação da TEMA numa fábrica ou setor industrial é um processo complexo, envolvendo diversos interesses econômicos, sociais e possibilidades técnicas dentro do estágio de desenvolvimento científico e tecnológico da sociedade. A crescente preocupação com a qualidade de vida e os problemas ecológicos decorrentes do industrialismo vem levando a uma maior consciência da necessidade de incorporarmos critérios ecológicos e de saúde na definição dos critérios que norteiam o desenvolvimento e seleção de tecnologias de fabricação. Neste sentido, a busca da implementação de tecnologias ecologicamente adequadas nos diversos setores industriais pode servir como meta estratégica no desenvolvimento futuro do parque industrial brasileiro.

A possibilidade de implementação de TEMA's nos diversos setores industriais depende também da criação de fóruns amplos, 
onde os diversos atores envolvidos com o desenvolvimento industrial no país possam participar da definição dos critérios e metas de investimento industrial. Destacamos o potencial das câmaras setoriais recentementes criadas no país, das negociações coletivas de trabalho por categoria a nível nacional, da abertura à participação aos trabalhadores e grupos ecológicos pelos bancos de financiamento e fomento de projetos industriais, da atuação do Ministério Público na criação de fóruns legais na defesa dos direitos constitucionais, e da atuação consequente e aberta das autoridades governamentais vinculadas ao problema como importantes espaços para o desenvolvimento ecológico do parque industrial brasileiro.

O caso da indüstria de cloro-soda é apenas um dos inúmeros setores industriais no Brasil que precisam receber a devida atenção de cidadãos, trabalhadores e autoridades, se quisermos evitar problemas ecológicos e de saúde, tanto prementes como futuros. Com o processo de democratização no país, tal processo vem ocorrendo de forma cada vez mais intensa, e certamente um importante passo estará sendo dado quando processos industriais obsoletos e degradantes forem substituídos por tecnologias ecologicamente mais adequadas. Mas, para isso, é necessário que todas as pessoas envolvidas possam receber informações adequadas sobre os riscos provocados pela industrialização e participar nas políticas que regulam tais riscos.

\section{Referências Bibliográficas}

ABICLOR. Mercúrio e Indústria de Cloro Cáustica/Soda. Estudos Técnicos n.1, Rio de Janeiro, 1992.
DWYER, T. The Industrial Safety Professionals: A Comparative Analysis from World I until the 1980's; In: International Journal of Public Health Services, vol.22, n. 4, p.705-27, 1992

MATTOS,U et alii. A Indústria de CloroSoda: Levantamento e Diagnóstico das Condições de Trabalho. Relatório de Pesquisa/FAPERJ. CESTEH/ENSP/ FIOCRUZ. 1993

MAXSON, P.A. et al. Mercury: Rational Paths Through Uncharted Territory. Commision of the European Communities, Bruxelas, 1991.

PORTO,M. Projeto Preliminar de Doutoramento. Programa de Engenharia de Produção, COPPE/UFRJ, 1994.

SCHADOW et al. 100 Jahre technische Alkali-Elektrolyse- Technologiewandel unter Umweltaspekten. In: Chem.-Ing.Tech.63, Nr.7, p.668-674. 